\title{
Factors associated With eMployee engagement in South Africa
}

\section{Authors:}

Sebastiaan Rothmann ${ }^{1,2}$

Sebastiaan Rothmann Jr

\section{Affiliations:}

1School of Behavioural

Sciences, North-West

University, Vanderbijlpark,

South Africa

${ }^{2}$ Department of Human

Sciences, University of

Namibia, Namibia

Correspondence to: Sebastiaan Rothmann

email:

ian@ianrothmann.com

Postal address:

PO Box 11789, Klein

Windhoek, Namibia

\section{Keywords:}

engagement; psychological conditions; job demands; job resources; antecedents

\section{Dates:}

Received: 17 Aug. 2010

Accepted: 05 May 2010

Published: 03 Dec. 2010

How to cite this article:

Rothmann, S., \&

Rothmann, S. (2010).

Factors associated with employee engagement in South Africa. SA Journal of Industrial Psychology/SA Tydskrif vir Bedryfsielkunde, 36(2), Art. \#925, 12 pages, DOI: 10.4102/sajip.v36i2.925

This article is available at:

http://www.sajip.co.za

(C) 2010. The Authors.

Licensee: OpenJournals Publishing. This work is licensed under the Creative Commons Attribution License.

\section{ABSTRACT}

Orientation: Knowledge of the factors associated with employee engagement is important for practitioners and researchers in industrial/organisational psychology in South Africa.

Research purpose: The objective of this study was to investigate the factors associated with employee engagement using two models, namely the personal engagement model of Kahn (1990), and the work engagement model of Schaufeli and Bakker (2004).

Motivation for the study: Scientific knowledge is needed regarding the factors that are associated with employee engagement.

Research design, approach and method: Survey designs were used with two samples taken from various South African organisations ( $n=467$ and $n=3775)$. The Work Engagement Scale, the Psychological Conditions Scale and the Antecedents Scale were administered for purposes of study 1. The Utrecht Work Engagement Scale and the Job Demands-Resources Scale were administered for purposes of study 2 .

Main findings: The results of study 1 showed that two psychological conditions, namely psychological meaningfulness and psychological availability, were positively associated with employee engagement. Work role fit was the best predictor of psychological meaningfulness and employee engagement. The results of study 2 showed that all job resources were positively associated with employee engagement. Organisational support and growth opportunities were the best predictors of vigour, dedication and absorption.

Pratical/managerial implications: Interventions to increase employee engagement should focus on work role fit. Job resources, including an intrinsically rewarding job, organisational support and advancement opportunities should be made available to increase employees' engagement.

Contribution/value-add: This study isolated the most important factors associated with employee engagement in South Africa.

\section{INTRODUCTION}

Employee engagement has become an important topic, not only for academics and researchers but also for practitioners in organisations (May, Gilson \& Harter, 2004; Schaufeli \& Bakker, 2004; Strümpfer, 2003). Various factors contribute to the academic interest in employee engagement. Firstly, a qualitative study was conducted by Kahn (1990) to conceptualise personal engagement in work roles and to identify the psychological conditions and antecedents thereof. Based on the model of Kahn (1990), May et al. (2004) and Olivier and Rothmann (2007) tested structural models of employee engagement. Secondly, interest in engagement arose with the shift in focus in psychology from weaknesses, malfunctioning and damage towards happiness, human strengths and optimal functioning (Rothmann, 2003; Strümpfer, 2003; Seligman \& Csikszentmihalyi, 2000). Peterson, Nansook and Seligman (2005) regarded the study and promotion of happiness as important goals of psychology and suggested three routes to happiness, namely pleasure, engagement and meaning. Engagement, as a component of happiness, entails that individuals pursue gratification by applying their strengths. Thirdly, in the burnout literature (Maslach \& Leiter, 1997), interest arose in engagement (energy, involvement and efficacy) as the direct opposite of burnout (exhaustion, cynicism and low professional efficacy). Lastly, research by Schaufeli, Salanova, González-Romá and Bakker (2002) stimulated studies regarding employee engagement as the antipode of burnout, but a construct in its own right (e.g. Fourie, Rothmann \& Van de Vijver, 2008; Hakanen, Schaufeli \& Ahola, 2008; Rothmann \& Joubert, 2007; Rothmann \& Pieterse, 2007; Schaufeli \& Bakker, 2004).

The needs of businesses to maximise the inputs of employees have also contributed to the interest in engagement. Business needs are driven by intense, often global, competition, which is increasing the need for employees to be emotionally and cognitively committed to their company, their customers and their work. Employee engagement predicts positive organisational outcomes, including productivity, job satisfaction, motivation, commitment, low turnover intention, customer satisfaction, return on assets, profits and shareholder value (Bakker, Demerouti \& Schaufeli, 2003; Bakker, Schaufeli, Leiter \& Taris, 2008; Harter, Schmidt \& Hayes, 2002; Schaufeli \& Bakker, 2004). Engagement affects the mindset of employees, and relates to personal initiative and learning (Sonnentag, 2003). Furthermore, it fuels discretionary efforts and concerns for quality (Salanova, Llorens, Cifre, Martinez \& Schaufeli, 2003).

Macey and Schneider (2008) distinguished three broad conceptualisations of employee engagement, namely state, trait, and behavioural engagement. State engagement, which is relevant for purposes of this study, can be defined from two perspectives, namely engagement as an extension of the self to a role (Kahn, 1990), and employees' work activities as a reference for engagement (Bakker et al., 2008; Schaufeli et al., 2002). Kahn (1990, p. 694) defined engagement as the 'harnessing of organizational members' 
selves to their work role by which they employ and express themselves physically, cognitively and emotionally during role performance'. Employees who are engaged put much effort into their work because they identify with it. Schaufeli et al. (2002), on the other hand, defined employee engagement as a positive, fulfilling, work-related state of mind characterised by vigour, dedication, and absorption. Vigour refers to high levels of energy and mental resilience while working, and the willingness to invest effort in one's work. Dedication refers to deriving a sense of significance from one's work, by feeling enthusiastic and proud about one's job, and by feeling inspired and challenged by it. Absorption is characterised by being totally and happily immersed in one's work and having difficulty detaching oneself from it.

Based on the perspectives of Kahn (1990) and Schaufeli et al. (2002), it can be concluded that employee engagement comprises three dimensions, namely a physical component (being physically involved in a task and showing vigour and a positive affective state), a cognitive component (being alert at work and experiencing absorption and involvement), and an emotional component (being connected to one's job/others while working, and showing dedication and commitment). Whilst thousands of articles have appeared on burnout (which is the antipode of engagement), research on employee engagement has just begun to emerge (Bakker et al., 2008). However, it is clear that research on employee engagement and the factors associated with it is needed, because modern organisations expect employees to be engaged, proactive, committed to high quality performance standards, and to take responsibility for their own development.

Studies (both internationally and in South Africa) have shown that engagement can be measured in a valid and reliable way using the Utrecht Work Engagement Scale (Bakker et al., 2008; Barkhuizen \& Rothmann, 2006; Schaufeli et al., 2002; Storm \& Rothmann, 2003) and the Work Engagement Scale (May et al., 2004; Olivier \& Rothmann, 2007). Regarding the drivers of employee engagement, two studies that build on the model of Kahn (1990) have been traced (May et al., 2004; Olivier \& Rothmann, 2007). Studies have also been conducted utilising the perspective on engagement of Schaufeli et al. (2002). These studies focused on the effect of job demands and resources on employee engagement both internationally (e.g. Schaufeli \& Bakker, 2004) and in South Africa (e.g. Jackson, Rothmann \& Van de Vijver, 2006; Rothmann \& Joubert, 2007; Rothmann \& Pieterse, 2007).

From the above-mentioned discussion it should be clear that it is necessary to investigate the factors associated with employee engagement in South Africa. The personal engagement model of Kahn (1990) focuses on engagement as an extension of the self, whilst the work engagement model of Schaufeli and Bakker (2004) focuses on work activities (from a social exchange theory perspective) as a reference for engagement (Bakker et al., 2008). The perspectives of Kahn (1990) and Schaufeli and Bakker (2004) provide useful conceptualisations of the drivers of employee engagement, but a need exists to investigate the drivers of employee engagement according to these models in South African organisations. The objective of this study was to investigate the factors associated with employee engagement from the perspective of two models, namely the personal engagement model of Kahn (1990) and the work engagement model of Schaufeli and Bakker (2004), in South Africa.

\section{Engagement as an extension of the self}

According to Kahn (1990), people can use varying degrees of their selves, physically, cognitively, and emotionally, in the work they perform. It seems that the more people draw on their selves to perform their roles the more stirring their performances. Furthermore, engagement is the simultaneous employment and expression of a person's preferred self in task behaviours that promote connections to work and to others. The combination of employing and expressing a person's preferred self yields behaviours that bring alive the relation of self to role. Individuals who are engaged become physically involved in tasks, are cognitively vigilant, and become connected to others in the service of work they are doing (Kahn, 1990).

The idea behind Kahn's theory of personal engagement (Kahn, 1990) relates to the identification of three psychological conditions that impact on an individual's engagement, namely psychological meaningfulness, psychological safety, and psychological availability. Psychological meaningfulness refers to 'a feeling that one is receiving a return on investment of one's self in a currency of physical, cognitive or emotional energy' (Kahn, 1990, pp. 703-704). Psychological meaningfulness refers to the value of a work goal in relation to the ideals of an individual (Hackman \& Oldham, 1980). A lack of meaning in work can lead to apathy and detachment from one's work (Thomas \& Velthouse, 1990) and disengagement (May et al., 2004). Individuals are usually estranged from their selves under these kinds of conditions and restoration of meaning in work is a method of fostering an individual's motivation and attachment to work (Seeman, 1972). The studies of May et al. (2004) and Olivier and Rothmann (2007) confirmed that psychological meaningfulness is a strong predictor of employee engagement.

Psychological safety entails feeling able to show and employ one's self without fear of negative consequences to self-image, status or career (Kahn, 1990). Individuals who are working in a safe environment will understand the boundaries surrounding acceptable behaviours. Psychological safety might lead to engagement, because it reflects one's belief that a person can employ themself without fear of negative consequences. The opposite would occur in a work environment that is ambiguous, unpredictable and threatening. Employees in unsafe environments with ambiguous, unpredictable and threatening conditions are likely to disengage from the work, and would be more cautious to try new things. Although the study of May et al. (2004) confirmed a positive association between psychological safety and engagement, Olivier and Rothmann (2007) could not find such an association.

Psychological availability can be defined as the sense of having the physical, emotional or psychological resources to engage at a particular moment. It indicates whether the individual is ready and/or confident to engage in their work role given the fact that people are also engaged in many other life activities. Factors such as the individual's resources or work role insecurities might influence an individual's beliefs, which might have a direct influence on their psychological availability. May et al. (2004) and Olivier and Rothmann (2007) confirmed that psychological availability is positively associated with employee engagement.

Based on the above discussion, the following hypotheses are formulated:

Hypothesis 1a: Psychological meaningfulness is positively related to employee engagement.

Hypothesis 1b: Psychological safety is positively related to employee engagement.

Hypothesis 1c: Psychological availability is positively related to employee engagement.

Two factors in the work context contribute to psychological meaningfulness, namely work role fit and good co-worker relations (Kahn, 1990). Individuals seek work roles in which they can express their authentic selves fully in creative ways. Fit between an individual's self-concept and their work role will lead to a sense of meaning due to the ability of the individual to express their values and beliefs (Shamir, 1991). Employees 
should experience more meaning in the work environment when they have rewarding interpersonal interactions with their colleagues (Locke \& Taylor, 1990). Individuals will experience a sense of meaningfulness from their interactions when they are treated with respect and dignity and are valued for their contributions. The level of interaction an individual has with their co-workers will also foster a stronger sense of social identity, a sense of belonging and greater meaningfulness (Kahn, 1990).

The following hypotheses are formulated regarding the relationship between psychological meaningfulness, work role fit, and supportive co-worker relationships:

Hypothesis 2a: Work-role fit leads to psychological meaningfulness.

Hypothesis 2b: Good co-worker relationships lead to psychological meaningfulness.

Supervisory and co-worker relations that are supportive, trustworthy as well as flexible with regard to the behavioural norms lead to feelings of psychological safety (Kahn, 1990; May et al., 2004). Edmondson (2004) indicated that a supportive supervisor who is not controlling at work would have subordinates who experience a sense of safety in the work environment. Supervisor trustworthiness can be linked to five categories of behaviour, namely behavioural consistency, behavioural integrity, sharing and delegation of control, accurate and open communication, and a demonstration of concern (May et al., 2004). Managerial reluctance to loosen their control can send a message to their employees that they are not to be trusted, which might cause employees to be afraid of taking any chances or of overstepping their boundaries. This fear will be strengthened when managers behave unpredictably, inconsistently or hypocritically (Kahn, 1990; May et al., 2004). Trustworthy supervisory behaviours should lead to feelings of psychological safety, as well as willingness among employees to invest themselves at work. Interpersonal trust can either have cognitive or affective bases (McAllister, 1995). The reliability and dependability of others are related to cognitive-based trust, where the emotional relationships between individuals impact on affective trust.

Organisations are governed by attitudes, behaviour and the emotional dimensions of work (Hochschild, 1983). As long as individuals stay within the boundaries of appropriate behaviour they will experience psychological safety at work (Kahn, 1990). Group norms refer to the informal rules groups accept to regulate group members' behaviours (Feldman, 1984). Norms are enforced if, (1) they facilitate the survival of a group, (2) make group member behaviour more predictable, (3) assist the group to avoid embarrassing interpersonal problems and (4) express the core values of the group (Kahn, 1990). If employees feel they must follow the group norms, it would lead to feelings of less psychological safety than when they feel they are allowed more flexibility in their behaviour.

The following hypotheses are formulated regarding the relationship between psychological safety, supervisory relations, co-worker relations and co-worker norms:

Hypothesis 3a: Supportive supervisor relations are positively related to psychological safety.

Hypothesis 3b: Rewarding co-worker relations are positively related to psychological safety.

Hypothesis 3c: Adherence to co-worker norms is negatively related to psychological safety.

When engaging themselves at work, individuals depend on their specific physical, emotional and cognitive resources to complete work-related tasks. Different jobs require various and different kinds of physical exertion and challenges, which can result in injuries (May et al., 2004). Less physical challenging jobs, like sitting at a desk, can also put tremendous stress on an individual's back (Hollenbeck, Ilgen \& Crampton, 1992). Individuals vary in their stamina, flexibility and strength to successfully meet these physical challenges. Lacking these physical resources can lead to disengagement from one's work role. Emotional demands, especially in the services sector, require emotional labour (Hochschild, 1983; Sutton, 1991). According to Morris and Feldman (1996), continuing emotional demands could lead to the depletion of emotional resources (i.e. exhaustion), and furthermore, the frequency, duration, intensity and variety thereof can decrease these recourses. The consequences are that these individuals become overwhelmed by the amounts of information they need to process and as a result their ability to think clearly diminishes.

The expectation is that the presence of resources (physical, emotional and cognitive) would lead to greater availability and engagement. Those individuals who experience an overload tend to withdraw or disengage from their work in order to replenish their energy levels (Ganster \& Schaubroeck, 1991). When employees receive physical, emotional and cognitive resources from their organisation, they feel obliged to repay the organisation with greater levels of engagement (Kahn, 1990; Saks, 2006).

Self-consciousness has an influence on an employee's feeling of work role security, by distracting them to focus on external rather than internal cues (Kahn, 1990; May et al., 2004). Employees' psychological availability may suffer when they feel insecure and preoccupied with the impression they leave on others. May et al. (2004) found that self-consciousness is a negative predictor of psychological safety.

The following hypotheses are formulated regarding the relationship between psychological availability, resources and self-consciousness:

Hypothesis 4a: Resources are positively related to psychological availability.

Hypothesis 4b: Self-consciousness is negatively related to psychological availability.

The three psychological conditions that are explored, namely psychological meaningfulness, safety, and availability, will influence employees' engagement. If employees see work roles as being meaningful to them they will most likely engage more in their work. Psychological safety should also lead to employee engagement, because it confirms the individual's belief that he or she can voice his/her opinion without facing any negative consequences. Where the environment of an individual is ambiguous, unpredictable, and threatening, it is likely that they will disengage from work. An employee should be more willing to engage in work roles if he or she believes that he or she has the necessary physical, emotional and cognitive resources to do that (May et al., 2004).

The following research hypotheses are formulated regarding the relationships between the antecedent conditions, psychological conditions, and employee engagement:

Hypothesis 5a: Psychological meaningfulness mediates the effect of work role fit and co-worker relations on employee engagement.

Hypothesis 5b: Psychological safety mediates the effect of supervisory relations, co-worker relations and co-worker norms on employee engagement.

Hypothesis 5c: Psychological availability mediates the effect of resources and self-consciousness on employee engagement. 


\section{Work activities as a reference for engagement}

According to Bakker et al. (2008), research on burnout has stimulated research on employee engagement. Maslach and Leiter (1997, p. 23) define burnout as 'an erosion of engagement with the job'. The view of these authors is that employee engagement is characterised by energy, involvement and efficacy (i.e. the direct opposites of exhaustion, cynicism and low professional efficacy, which were identified as the dimensions of burnout). In contradiction to this view, Schaufeli et al. (2002) point out that although engagement is negatively related to burnout, it is an independent and distinct concept characterised by three dimensions, namely vigour, dedication, and absorption at work. Engagement, according to Bakker et al. (2008), focuses on employees' experiences of work activity.

Bakker et al. (2008) regard job and personal resources as important factors associated with employee engagement. Therefore most of the research on engagement as an experience of work activity has utilised the Job Demands-Resources (JDR) model (Demerouti, Bakker, Nachreiner \& Schaufeli, 2001; Hakanen et al., 2008), and the Conservation of Resources (COR) theory (Hobfoll, 1989, 1998) to study the factors associated with engagement.

The JD-R model assumes that although every occupation may have specific work characteristics associated with well-being, it is possible to model these characteristics in two broad categories, namely job demands and job resources (Demerouti et al., 2001). Job demands refer to those physical, psychological, social or organisational aspects of the job that require sustained physical and/or psychological effort, and that are therefore associated with certain physiological and/or psychological costs (e.g. work pressure, role overload and emotional demands). Job resources refer to those physical, psychological, social or organisational aspects of the job that may be functional in achieving work goals, reducing job demands and stimulating personal growth and development. Resources may be located at the level of the organisation (e.g. salary, career opportunities, job security), interpersonal and social relations (e.g. supervisor support, coworker support and team climate), the organisation of work (e.g. role clarity and participation in decision making), and the level of the task (e.g. performance feedback, skill variety, task significance, task identity and autonomy).

Rothmann, Strydom and Mostert (2006) developed a questionnaire to identify job demands and resources as conceptualised in the JD-R model. They found that job demands and resources consist of five factors, namely (1) overload, (2) job insecurity, (3) growth opportunities, advancement and (4) organisational support. Overload refers to the amount of work, mental load, and emotional load. Job insecurity refers to feeling insecure in the current job and level with regard to the future thereof. Growth opportunities refer to having enough variety, opportunities to learn, and independence. Advancement means moving forward within an organisation, and includes remuneration, training, and career opportunities. Organisational support refers to relationships with the supervisor, the availability of information, communication, participation, social support by colleagues, and contact opportunities within the organisation.

According to Bakker et al. (2008), job resources may play either an intrinsic motivational role (by fostering the employee's growth, learning and development), or an extrinsic motivational role (by being instrumental in achieving work goals). Regarding the intrinsic motivational role, job resources may fulfil the basic needs of employees in terms of autonomy, competence, and relatedness (Ryan \& Deci, 2000, 2001). Organisational support and growth opportunities foster learning, thereby increasing competence for the job. The participation and autonomy implied in both organisational support and growth opportunities may fulfil the need for autonomy. Social support by the supervisor and co-workers may fulfil the need for relatedness. Job resources may also play an extrinsic motivational role, because the availability of resources such as organisational support, growth opportunities, social support, and advancement may foster a willingness to dedicate one's efforts to the task, which will result in goal attainment. The satisfaction of needs and the achievement of work goals will result in engagement (Bakker et al., 2008).

The COR theory (Hobfoll, 1989, 1998) is a relevant theory for understanding the effects of job resources (or the lack thereof) on employees. The COR theory's central tenet is that people strive to obtain, retain and protect what they value. When the external environment lacks resources, individuals cannot reduce the potentially negative influence of high job demands, achieve their work goals, and develop themselves. The COR theory predicts that in such a situation employees will experience a loss of resources or failure to gain an investment (Hobfoll, 1989). Moreover, in order to reduce this discomfort or job stress, employees will attempt to minimise losses. With the intention of achieving equity without suffering further negative personal consequences, they will most probably reduce their discretionary inputs.

Various studies have shown that job resources, including social support from supervisors and colleagues, and the intrinsic nature of the job (e.g. skill variety, autonomy and learning opportunities) are positively associated with employee engagement (Bakker et al., 2008; Schaufeli \& Bakker, 2004). In a longitudinal study, Mauno, Kinnunen and Ruokolainen (2007) found that job resources predicted employee engagement better than job demands. Hakanen et al. (2008) conducted a longitudinal study and found that job resources predicted future engagement. Rothmann and Pieterse (2007) studied the relationship between job resources and employee engagement and found that growth opportunities in the job (i.e. variety, learning opportunities and autonomy) best predicted employee engagement. Rothmann and Joubert (2007) found that organisational support and growth opportunities in the job were strong predictors of employee engagement in the mining industry. High job resources, such as social support and feedback, may reduce the effects of job demands (Demerouti et al., 2001).

The following hypotheses are formulated regarding the relationship between job demands, job resources, and employee engagement:

Hypothesis 6a: Job resources are positively related to employee engagement.

Hypothesis 6b: Job demands interact with job resources to affect employee engagement.

\section{RESEARCH DESIGN}

\section{Research approach}

A survey design was used in this study. Questionnaires were used to gather data in a non-random field survey.

\section{Research method}

\section{Participants}

Table 1 shows some of the characteristics of the participants in study 1 .

Participants in study 1 represented three organisations, namely a multinational oil company (36.6\%), an organisation in the chemical industry (35.3\%) and a financial institution (28.1\%). Table 2 shows some of the characteristics of the participants in study 2 . 
TABLE 1

Characteristics of the participants (study 1 )

\begin{tabular}{|c|c|c|c|}
\hline Item & Category & $N$ & $\%$ \\
\hline \multirow[t]{3}{*}{ Organisation } & Multinational oil company & 171 & 36.6 \\
\hline & Chemical organisations & 165 & 35.3 \\
\hline & Financial institution & 131 & 28.1 \\
\hline \multirow[t]{8}{*}{ Age } & $18-27$ years & 51 & 10.9 \\
\hline & $28-32$ years & 67 & 14.3 \\
\hline & $33-38$ years & 82 & 17.6 \\
\hline & $39-44$ years & 74 & 15.8 \\
\hline & $45-50$ years & 63 & 13.5 \\
\hline & $51-56$ years & 61 & 13.1 \\
\hline & $>56$ years & 29 & 6.20 \\
\hline & Missing values & 16 & 3.40 \\
\hline \multirow[t]{6}{*}{ Education level } & Lower than Grade 12 & 138 & 29.5 \\
\hline & Grade 12 & 184 & 39.4 \\
\hline & 3 years post-school qualification & 87 & 18.6 \\
\hline & 4 years post-school qualification & 37 & 7.90 \\
\hline & $\begin{array}{l}\text { More than } 4 \text { years post-school } \\
\text { qualification }\end{array}$ & 14 & 3.00 \\
\hline & Missing Values & 7 & 1.50 \\
\hline \multirow[t]{3}{*}{ Gender } & Male & 207 & 44.3 \\
\hline & Female & 249 & 53.3 \\
\hline & Missing values & 11 & 2.40 \\
\hline \multirow[t]{4}{*}{ Home language } & Afrikaans & 168 & 36.0 \\
\hline & English & 144 & 30.8 \\
\hline & African & 147 & 31.5 \\
\hline & Missing values & 8 & 1.70 \\
\hline
\end{tabular}

TABLE 2

Characteristics of the participants (study 2)

\begin{tabular}{|c|c|c|c|}
\hline Item & Category & Frequency & $\%$ \\
\hline \multirow[t]{6}{*}{ Organisation } & Correctional services & 892 & 23.6 \\
\hline & Educators (Schools) & 1177 & 31.2 \\
\hline & Engineers & 369 & 9.80 \\
\hline & Insurance & 613 & 16.2 \\
\hline & $\begin{array}{l}\text { Non-academic staff } \\
\text { (higher education) }\end{array}$ & 352 & 9.30 \\
\hline & University of Technology & 372 & 9.90 \\
\hline \multirow[t]{8}{*}{ Age } & $18-27$ years & 281 & 7.44 \\
\hline & $28-32$ years & 665 & 17.72 \\
\hline & $33-38$ years & 861 & 22.82 \\
\hline & $39-44$ years & 708 & 18.76 \\
\hline & $45-50$ years & 473 & 12.53 \\
\hline & $51-56$ years & 285 & 7.54 \\
\hline & $>56$ years & 207 & 5.48 \\
\hline & Missing values & 295 & 7.81 \\
\hline \multirow[t]{5}{*}{ Education level } & Grade 12 or lower & 1684 & 44.61 \\
\hline & 3-year qualification & 988 & 26.17 \\
\hline & 4-year qualification & 702 & 18.6 \\
\hline & $\begin{array}{l}\text { More than 4-year } \\
\text { qualification }\end{array}$ & 353 & 9.35 \\
\hline & Missing values & 48 & 1.27 \\
\hline \multirow[t]{2}{*}{ Gender } & Male & 1872 & 49.59 \\
\hline & Female & 1903 & 50.41 \\
\hline \multirow[t]{4}{*}{ Home language } & Afrikaans & 1532 & 40.58 \\
\hline & English & 672 & 17.8 \\
\hline & African & 1529 & 40.6 \\
\hline & Missing values & 42 & 1.11 \\
\hline
\end{tabular}

Participants in study 2 represented six organisations, namely correctional services $(23.6 \%)$, educators in primary and secondary schools (31.2\%), engineers in various engineering companies $(9.8 \%)$, employees in the insurance industry $(16.2 \%)$, non-academic staff of higher education institutions (9.3\%) and staff members of a university of technology (9.9\%).

\section{Measuring instruments}

The Antecedents Scale, Psychological Conditions Scale and the Work Engagement Scale were used in study 1.

The Antecedents Scale (AS; May et al., 2004) was used to measure participants' perceptions of themselves, their jobs, supervisors, and co-workers. All scales are based on a 5-point agreementdisagreement Likert format with 1 (strongly disagree) and 5 (strongly agree). Work role fit was measured by four items that directly measures individuals' perceived fit with their jobs and self-concept (e.g. 'My job 'fits' how I see myself.'). Co-worker relations were measured by ten items (e.g. 'My interactions with my co-workers are rewarding.'). Supportive supervisor relations were measured by ten items (e.g. 'My supervisor helps me solve work-related problems.'). Co-worker norm adherence was measured by three items (e.g. 'I go along with the norms in my group of co-workers.'). The degree to which individuals possess the resources to become available for engagement is assessed by eight items (e.g. 'I feel mentally sharp at the end of the workday.'). Self-consciousness was measured by three items (e.g. 'I worry about how others perceive me at work.'). May et al. (2004) found alpha coefficients varying between 0.82 (selfconsciousness) and 0.95 (supportive supervisor relations) in an insurance firm.

The Psychological Conditions Scale (PCS) was used to measure psychological meaningfulness, psychological safety, and psychological availability. Six items $(\alpha=0.90)$, drawn from Spreitzer (1995) and May et al. (2004), measure the degree of psychological meaningfulness individuals experience in their work-related activities, e.g. 'The work I do in this job is very important to me.' Psychological safety is measured by three items ( $\alpha=0.71)$, based on Kahn's study (Kahn, 1990), e.g. 'I'm not afraid to be myself at work.' These items assess whether individuals feel comfortable in being themselves and expressing their opinions at work or whether there is a threatening environment at work. The confidence individuals have regarding their ability to be cognitively, physically, and emotionally available for work is measured by an average of five items $(\alpha=0.85)$, based on Kahn's study (Kahn, 1990), e.g. 'I am confident in my ability to handle competing demands at work').

The Work Engagement Scale (WES; May et al., 2004) was used to measure employee engagement. Employee engagement was measured by using an average of 13 items $(\alpha=0.77)$. The items reflect each of the three components of Kahn's conceptualisation of engagement (Kahn, 1990): cognitive (e.g. 'Performing my job is so absorbing that I forget about everything else'), emotional (e.g. 'I really put my heart into my job') and physical (e.g. 'I exert a lot of energy performing my job').

The Utrecht Work Engagement Scale and the Job DemandsResources Scale were used in study 2.

The Utrecht Work Engagement Scale (UWES; Schaufeli et al., 2002) was used to measure employee engagement. The UWES consists of 17 items that measure three sub-scales, and includes statements such as 'I am bursting with energy every day in my work' (vigour), 'My job inspires me' (dedication) and 'Time flies when I am at work' (absorption). The UWES is scored on a seven-point frequency rating scale, varying from 0 (never) to 6 (always). Research in various countries (including South Africa) showed that the fit of the hypothesised three-factor structure to the data was superior to that of alternative factor models. Storm 
and Rothmann (2003) obtained the following alpha coefficients for the UWES in South Africa: vigour: 0.78, dedication: 0.89 and absorption: 0.78 .

The Job Demands-Resources Scale (JD-RS) was used to measure job demands and job resources of employees. The JD-RS was developed by Rothmann et al. (2006) and comprises 46 items. The questions are rated on a four-point scale, ranging from 1 (never) to 4 (always). Exploratory factor analysis indicated that five factors could be extracted using the JD-RS, namely overload, organisational support, growth opportunities, advancement and job security. Social support by colleagues loaded on a separate factor in some studies, and on organisational support in other studies. Rothmann et al. (2006) obtained the following alpha coefficients for the JD-RS over a range of occupations and organisations in South Africa: overload: 0.76, organisational support: 0.92, growth opportunities: 0.86 , advancement: 0.83 and job insecurity: 0.89 .

A questionnaire was developed to gather information regarding the demographic characteristics of the participants.

\section{Research procedure}

The researchers administered hard copies of the questionnaires on participants in the different organisations. The questionnaires were completed anonymously by participants and collected by the researchers after completion thereof. All ethical guidelines in the treatment of human subjects in research were observed in all the steps of the study.

\section{Data analysis}

Data analysis was carried out with the SPSS 16.0 programme (SPSS, 2008). Exploratory factor analyses were conducted to confirm that the measures were distinct from one another. All the variables were used in a principal factor analyses with a direct oblimin rotation. A cut-off point of 0.40 was used for cross-loadings. For purposes of study 1 , the factors of the WES PCS and AS were factor analysed. The factor analysis identified 13 factors with eigenvalues greater than 1.00. The largest factor explained $20.49 \%$ of the variance and was composed of all the supervision items. All scale items loaded on their respective constructs and did not cross-load on the other factors. For purposes of study 2, the factors of the UWES and the JD-RS were factor analysed. The factor analysis identified seven factors with eigenvalues greater than 1.00. The largest factor explained $13.31 \%$ of the variance and was composed of all the organisational support items. All scale items loaded on their respective constructs and did not cross-load on the other factors. However, the UWES items all loaded on one factor, while structural equation modelling showed support for a threefactor rather than a one-factor structure. Overall, the results of these factor analyses lend support to the discriminant validity of the measures and did not suggest that common method variance was a problem in the data according to Harmon's onefactor test for common method bias (Podsakoff \& Organ, 1986).
The reliability of the measuring instruments was assessed by means of Cronbach alpha coefficients. Descriptive statistics (means and standard deviations) were computed to describe the data. Pearson product-moment correlation coefficients were used to specify the relationships between the variables. The level of statistical significance was set at $p<0.05$. Effect sizes (Steyn, 1999) were used to decide on the practical significance of the findings. A cut-off point of 0.30 (medium effect) (Cohen, 1988) was set for the practical significance of correlation coefficients.

Canonical correlation analysis was used to determine the relationships between the constructs. The goal of canonical correlation was to analyse the relationship between two sets of variables (Tabachnick \& Fidell, 2001). Furthermore, two types of regression analyses were used in this study. Firstly, standard multiple regression analyses were used to investigate the main effects of job resources and job demands on employee engagement. Secondly, a two-step hierarchical multiple regression analysis was conducted with the variables in their continuous form. In the first step, the predictor (i.e. job demands) and moderator (i.e. a specific job resource) were entered into the regression equation, followed by their interactions in the second step. The interaction term is represented by the product of the two main effects (i.e. job demands $x$ organisational support) (Aiken \& West, 1991). Furthermore, in line with the procedure suggested by these authors, the independent variable and the moderator were centred before testing for the significance of the interaction term. To centre a variable, scores are put into deviation score form by subtracting the sample mean from all individuals' scores on the variable, thus producing a revised sample mean of zero.

\section{RESULTS}

\section{Study 1}

\section{Descriptive statistics and correlations}

The descriptive statistics, alpha coefficients, and Pearson correlations of the PCS, the AS and the WES are reported in Table 3.

The alpha coefficients of most of the scales were acceptable compared with the cut-off point of 0.70 (Nunnally \& Bernstein, 1994). However, the alpha coefficients of three of the scales were lower than 0.70 , namely psychological safety $(\alpha=0.60)$, co-worker norms $(\alpha=0.62)$ and employee engagement $(\alpha=0.65)$.

Table 3 shows that employee engagement is statistically and practically significantly related to psychological meaningfulness $(r=0.43$, medium effect) and psychological availability $(r=0.31$, medium effect). Psychological meaningfulness is statistically and practically significantly related to work role fit $(r=0.63$, large effect). Psychological availability is statistically and practically significantly related to work role fit $(r=0.39$, medium effect) and co-worker relations $(r=0.31$, medium effect). Psychological

TABLE 3

Descriptive statistics, alpha coefficients, and Pearson correlations of the scales (study 1 )

\begin{tabular}{|c|c|c|c|c|c|c|c|c|c|c|c|c|c|}
\hline Item & & Mean & $S D$ & $a$ & 1 & 2 & 3 & 4 & 5 & 6 & 7 & 8 & 9 \\
\hline 1. & Psychological Meaningfulness & 20.41 & 4.23 & 0.91 & - & - & - & - & - & - & - & - & - \\
\hline 2. & Psychological Availability & 20.68 & 3.5 & 0.84 & $0.52^{*}+\dagger$ & - & - & - & - & - & - & - & - \\
\hline 3. & Psychological Safety & 5.74 & 2.42 & 0.60 & -0.06 & -0.02 & - & - & - & - & - & - & - \\
\hline 4. & Work Role Fit & 13.6 & 4.25 & 0.90 & $0.63^{*}+\dagger$ & $0.39^{*} \dagger$ & $-0.13^{*}$ & - & - & - & - & - & - \\
\hline 5. & Co-worker Relations & 32.56 & 7.66 & 0.94 & $0.26^{*}$ & $0.31^{*} \dagger$ & -0.07 & $0.33^{*} \dagger$ & - & - & - & - & - \\
\hline 6. & Supervisor Relations & 33.75 & 10.16 & 0.95 & $0.22^{*}$ & $0.16^{*}$ & $-0.12^{*}$ & $0.38^{*} \dagger$ & $0.44^{*} \dagger$ & - & - & - & - \\
\hline 7. & Resources & 23.54 & 6.08 & 0.78 & $0.10^{*}$ & $0.14^{*}$ & $0.38^{*} \dagger$ & $0.10^{*}$ & $0.13^{*}$ & $0.10^{*}$ & - & - & - \\
\hline 8. & Co-worker Norms & 7.16 & 1.69 & 0.62 & $0.29^{*}$ & $0.19^{*}$ & -0.03 & $0.26^{*}$ & $0.39^{*} \dagger$ & $0.33^{*} \dagger$ & $0.14^{*}$ & - & - \\
\hline 9. & Self-consciousness & 5.29 & 2.22 & 0.73 & $-0.15^{*}$ & $-0.26^{*}$ & 0.06 & $-0.14^{*}$ & $-0.14^{*}$ & 0.04 & -0.04 & 0.02 & - \\
\hline 10. & Employee Engagement & 32.45 & 4.85 & 0.65 & $0.43^{*} t$ & $0.31^{*} t$ & -0.06 & $0.26^{*}$ & $0.13^{*}$ & $0.16^{*}$ & 0.02 & $0.15^{*}$ & 0.03 \\
\hline
\end{tabular}


TABLE 4

Results of the canonical analysis: Psychological conditions and antecedents of employee engagement (study 1)

\begin{tabular}{|c|c|c|c|c|}
\hline & \multicolumn{2}{|c|}{ First canonical variate } & \multicolumn{2}{|c|}{ Second canonical variate } \\
\hline & Correlation & Coefficient & Correlation & Coefficient \\
\hline \multicolumn{5}{|l|}{$\begin{array}{l}\text { Psychological Conditions } \\
\text { Set }\end{array}$} \\
\hline Psychological Meaningfulness & -0.97 & -0.84 & 0.13 & 0.51 \\
\hline Psychological Availability & -0.66 & -0.22 & 0.27 & 0.26 \\
\hline Psychological Safety & 0.23 & 0.18 & 0.96 & 0.96 \\
\hline Percent of Variance & 0.47 & - & 0.34 & Total $=0.81$ \\
\hline Redundancy & 0.21 & - & 0.06 & Total $=0.27$ \\
\hline \multicolumn{5}{|l|}{$\begin{array}{l}\text { Antecedent Conditions } \\
\text { Set }\end{array}$} \\
\hline Work Role Fit & -0.96 & -0.89 & 0.01 & -0.00 \\
\hline Co-Worker Relations & -0.45 & -0.10 & 0.07 & 0.07 \\
\hline Supervisor Relations & -0.36 & 0.08 & -0.14 & -0.28 \\
\hline Resources & -0.07 & 0.05 & 0.97 & 0.99 \\
\hline Facilitative Norms & -0.43 & -0.19 & 0.09 & 0.02 \\
\hline Self-Consciousness & 0.30 & 0.17 & -0.03 & 0.03 \\
\hline Percent of Variance & 0.26 & - & 0.16 & Total $=0.42$ \\
\hline Redundancy & 0.11 & - & 0.03 & Total $=0.14$ \\
\hline Canonical correlation & 0.67 & - & 0.42 & - \\
\hline
\end{tabular}

safety is statistically and practically significantly related to resources $(r=0.39$, medium effect) and co-worker relations $(r=$ 0.38 , medium effect).

\section{Multivariate statistics}

Canonical analysis was performed relating the three psychological conditions and the antecedents. Table 4 shows the correlations between the variables and canonical variates, standardised canonical variate coefficients, within-set variance accounted for by the canonical va riates (percent of variance), redundancies and canonical correlations.

The first canonical correlation is 0.67 ( $45 \%$ overlapping variance). The other two canonical correlations are 0.42 and 0.25 . With all three canonical correlations included $F(18,1293.08)=55.79, p<$ 0,0001 . The second F-test $[F(10,916)=23.76, p<0.0001]$ and the third F-test $[F(4,459)=17.45, p<0.0001]$ are also statistically significant. In line with the recommendation of Tabachnick and Fidell (2001), only canonical correlations higher than 0.30 are interpreted here. The two pairs of canonical variates accounted for the significant relationships between the two sets of variables.

With a cut-off correlation of 0.30 , the variables in the psychological conditions set that were correlated with the first

TABLE 5

Regression analyses of psychological conditions and antecedent factors as independent variables on employee engagement as dependent variable (study 1 )

\begin{tabular}{|c|c|c|c|c|c|c|c|c|c|c|}
\hline \multirow[t]{2}{*}{ Model } & & \multicolumn{2}{|c|}{ Unstandardised Coefficients } & \multirow{2}{*}{$\frac{\text { Standardised Coefficients }}{\text { Beta }}$} & \multirow[t]{2}{*}{$t$} & \multirow[t]{2}{*}{$p$} & \multirow[t]{2}{*}{$F$} & \multirow[t]{2}{*}{$R$} & \multirow[t]{2}{*}{$R^{2}$} & \multirow[t]{2}{*}{$\Delta \boldsymbol{R}^{2}$} \\
\hline & & B & SE & & & & & & & \\
\hline \multicolumn{11}{|c|}{ Antecedents of Psychological Meaningfulness } \\
\hline \multirow[t]{5}{*}{1.1} & - & - & - & - & - & - & $16.67^{*}$ & 0.26 & 0.07 & $0.07^{\star}$ \\
\hline & (Constant) & 27.73 & 1.04 & - & 26.73 & 0.00 & - & - & - & - \\
\hline & Work Role Fit & 0.27 & 0.05 & 0.24 & 5.05 & $0.00^{*}$ & - & - & - & - \\
\hline & Co-worker Relations & 0.03 & 0.03 & 0.05 & 1.03 & 0.30 & - & - & - & - \\
\hline & & - & - & - & - & - & $34.81^{*}$ & 0.43 & 0.18 & $0.11^{*}$ \\
\hline \multirow[t]{4}{*}{1.2} & (Constant) & 22.11 & 1.19 & - & 18.56 & 0.00 & - & - & - & - \\
\hline & Work Role Fit & -0.03 & 0.06 & -0.03 & -0.53 & 0.60 & - & - & - & - \\
\hline & Co-worker Relations & 0.01 & 0.03 & 0.02 & 0.51 & 0.61 & - & - & - & - \\
\hline & Psychological Meaningfulness & 0.51 & 0.06 & 0.44 & 8.13 & $0.00^{*}$ & - & - & - & - \\
\hline \multicolumn{11}{|c|}{ Antecedents of Psychological Safety } \\
\hline \multirow[t]{6}{*}{2.1} & - & - & - & - & - & - & $4.78^{*}$ & 0.20 & 0.04 & $0.04^{*}$ \\
\hline & (Constant) & 27.36 & 1.32 & - & 20.69 & 0.00 & - & - & - & - \\
\hline & Supervisor Relations & 0.05 & 0.03 & 0.11 & 2.14 & $0.03^{*}$ & - & - & - & - \\
\hline & Co-worker Relations & 0.03 & 0.03 & 0.05 & 0.84 & 0.40 & - & - & - & - \\
\hline & Co-worker Norms & 0.28 & 0.15 & 0.10 & 1.95 & $0.05^{\star}$ & - & - & - & - \\
\hline & Self-consciousness & 0.07 & 0.10 & 0.03 & 0.64 & 0.53 & - & - & - & - \\
\hline \multirow[t]{7}{*}{2.2} & & - & - & - & - & - & $4.04^{*}$ & 0.21 & 0.04 & 0.00 \\
\hline & (Constant) & 27.96 & 1.44 & - & 19.36 & 0.00 & - & - & - & - \\
\hline & Supervisor Relations & 0.05 & 0.03 & 0.11 & 2.02 & $0.04^{*}$ & - & - & - & - \\
\hline & Co-worker Relations & 0.03 & 0.03 & 0.05 & 0.83 & 0.41 & - & - & - & - \\
\hline & Co-worker Norms & 0.29 & 0.15 & 0.10 & 1.96 & $0.05^{*}$ & - & - & - & - \\
\hline & Self-consciousness & 0.07 & 0.10 & 0.03 & 0.7 & 0.48 & - & - & - & - \\
\hline & Psychological Safety & -0.10 & 0.09 & -0.05 & -1.04 & 0.30 & - & - & - & - \\
\hline \multicolumn{11}{|c|}{ Antecedents of Psychological Availability } \\
\hline \multirow[t]{5}{*}{3.1} & - & - & - & - & - & - & 0.25 & 0.03 & 0.00 & 0.00 \\
\hline & Constant & 31.79 & 1.07 & - & 29.76 & 0.00 & - & - & - & - \\
\hline & Resources & 0.01 & 0.04 & 0.02 & 0.37 & 0.71 & - & - & - & - \\
\hline & Self-consciousness & 0.06 & 0.10 & 0.03 & 0.62 & 0.53 & - & - & - & - \\
\hline & & - & - & - & - & - & $19.43^{*}$ & 0.34 & 0.11 & $0.11^{*}$ \\
\hline \multirow[t]{4}{*}{3.2} & (Constant) & 21.62 & 1.68 & - & 12.9 & 0.00 & - & - & - & - \\
\hline & Resources & -0.02 & 0.04 & -0.03 & -0.64 & 0.52 & - & - & - & - \\
\hline & Self-consciousness & 0.26 & 0.10 & 0.12 & 2.61 & $0.01^{*}$ & - & - & - & - \\
\hline & Psychological Availability & 0.48 & 0.06 & 0.35 & 7.60 & $0.00^{*}$ & - & - & - & - \\
\hline
\end{tabular}

${ }^{*} p<0.05-$ statistically significant 
canonical variate are psychological meaningfulness (-0.97) and psychological availability (-0.66). Among the antecedents set, work role fit (-0.96), co-worker relations $(-0.45)$, supervisor relations (-0.36), facilitative norms $(-0.43)$ and low selfconsciousness $(0.30)$ correlate with the first canonical variate. The variable in the psychological conditions set that correlates with the second canonical variate is psychological safety (0.96). Among the antecedents set, one variable, namely resources (0.97), correlates with the second canonical variate

A multiple regression analysis was carried out with psychological meaningfulness, psychological availability, and psychological safety (as measured by the PCS) as independent variables and employee engagement (as measured by the WES) as dependent variable. The results showed that $19.7 \%$ of the variance in employee engagement is predicted by the three psychological conditions $(F=37.75, p<0.01)$. The beta coefficients of two factors, namely psychological meaningfulness $(\beta=$ 0.36 ) and psychological availability $(\beta=0.13)$, are statistically significant. Therefore, psychological meaningfulness and psychological availability are statistically significant predictors of employee engagement. Hypotheses $1 \mathrm{a}$ and $1 \mathrm{~b}$ are therefore accepted but Hypothesis 1c is rejected.

Next, a series of multiple regression analyses were performed to test whether the psychological conditions mediate the relationship between antecedents and employee engagement. Baron and Kenny (1986) recommend three steps in order to test for mediation. According to these authors, beta coefficients of different regression equations must be compared. Firstly, the mediator should be predicted by the independent variable. Secondly, the dependent variable should be predicted by the mediator and the independent variable, and lastly, the dependent variable should be regressed on the independent variable, controlling for the mediator. If all steps prove significant, perfect mediation holds when, controlling for the mediator, the independent variable does not predict the dependent variable.

A regression analysis with psychological meaningfulness (as measured by the PCS) as dependent variable and work role fit and co-worker relations (as measured by the AS) as independent variables was subsequently conducted. The results showed that the two variables predicted $40.3 \%$ of the variance in psychological meaningfulness $(F=135.85, p<0.01)$. The regression coefficient of one independent variable, namely work role fit, was statistically significant $(\beta=0.61, p<0.01)$.

The results in Table 5 indicate that work role fit and co-worker relations predicted $7 \%$ of the variance in employee engagement $(F=16.78, p<0.01)$. The regression coefficient of work role fit is statistically significant $(\beta=0.24, p<0.01)$. Hypothesis $2 \mathrm{a}$ is therefore accepted, but Hypothesis $2 b$ is rejected. In the second step of the regression analysis, psychological meaningfulness (as measured by the PCS) was entered with work role fit and co-worker relations (as measured by the AS) into the regression analysis. The results showed that an increase in the value of $R^{2} \quad\left(\Delta R^{2}=0.11, p<0.01\right)$ was recorded when psychological meaningfulness was entered into the regression analysis.
Furthermore, the regression coefficient of work role fit is not statistically significant when psychological meaningfulness is entered into the regression equation. Hypothesis $5 \mathrm{a}$ is therefore partially accepted.

A regression analysis with psychological safety (as measured by the PCS) as dependent variable and supervisor relations, $\mathrm{CO}^{-}$ worker relations, co-worker norms and self-consciousness (as measured by the AS) as independent variables was subsequently conducted. The results showed that none of the four independent variables are statistically significant predictors of psychological safety $(F=1.26, p>0.01)$. Hypotheses $3 \mathrm{a}, 3 \mathrm{~b}$ and $3 \mathrm{c}$ are therefore rejected. The results in Table 5 indicate that the antecedents of psychological safety predicted $4 \%$ of the variance in employee engagement $(F=4.78, p<0.01)$. The regression coefficient of two antecedents, namely supervisor relations $(\beta=0.11, p<0.01)$ and self-consciousness, are statistically significant $(\beta=0.10, p<0.01)$. In the second step, psychological safety (as measured by the PCS) was entered with the antecedents (as measured by the AS) into the regression analysis. No statistically significant increase in $R^{2}$ was recorded. Hypothesis $5 \mathrm{~b}$ is therefore rejected.

A regression analysis with psychological availability (as measured by the PCS) as dependent variable, and resources and self-consciousness (as measured by the AS) as independent variables was subsequently conducted. The results showed that the two variables predicted $9.5 \%$ of the variance in psychological availability $(F=22.62, p<0.01)$. The regression coefficient of both independent variables, namely resources $(\beta$ $=0.15, p<0.01)$ and self-consciousness $(\beta=0.27, p<0.01)$, are statistically significant. Hypotheses $4 \mathrm{a}$ and $4 \mathrm{~b}$ are therefore accepted. The results in Table 5 indicate that the antecedents of psychological availability did not predict employee engagement statistically significantly $(F=0.25, p>0.01)$. In the second step, psychological availability (as measured by the PCS) was entered with the antecedents (as measured by the AS) into the regression analysis. The results showed an increase in the value of $R^{2}\left(\Delta R^{2}=0.11, p<0.01\right)$ when psychological availability was entered into the regression analysis. However, psychological availability did not mediate the effect of its antecedent on employee engagement. Hypothesis $5 \mathrm{c}$ is therefore rejected.

\section{Study 2}

\section{Descriptive statistics and correlations}

The descriptive statistics, alpha coefficients and Pearson correlations of the UWES and the JD-RS are reported in Table 6.

The alpha coefficients of all the scales are higher than the cut-off point of 0.70 (Nunnally \& Bernstein, 1994). The results in Table 6 show that vigour is statistically and practically significantly related to organisational support $(r=0.41$, medium effect) and growth opportunities $(r=0.50$, medium effect). Dedication is also statistically and practically significantly related to organisational support $(r=0.44$, medium effect), and growth opportunities ( $r=0.58$, medium effect). Furthermore, absorption is statistically and practically significantly related to organisational support $(r=0.30$, medium effect) and growth opportunities $(r=0.40$, medium effect).

TABLE 6

Descriptive statistics, alpha coefficients and Pearson correlations of the scales (study 2)

\begin{tabular}{|c|c|c|c|c|c|c|c|c|c|c|c|c|}
\hline Iten & & Mean & $S D$ & $a$ & 1 & 2 & 3 & 4 & 5 & 6 & 7 & 8 \\
\hline 1. & Vigour & 21.3 & 5.82 & 0.71 & - & - & - & - & - & - & - & - \\
\hline 2. & Dedication & 22.74 & 6.62 & 0.85 & $0.76^{*}+\dagger$ & - & - & - & - & - & - & - \\
\hline 3. & Absorption & 23.44 & 6.92 & 0.67 & $0.58^{*}+\dagger$ & $0.57^{*}+\dagger$ & - & - & - & - & - & - \\
\hline 4. & Organisational Support & 42.81 & 9.22 & 0.91 & $0.41^{*} \dagger$ & $0.44^{*} \dagger$ & $0.30^{*} \dagger$ & - & - & - & - & - \\
\hline 5. & Growth Opportunities & 22.71 & 5.24 & 0.85 & $0.50 *+\dagger$ & $0.58^{*}+\dagger$ & $0.40^{*} \dagger$ & $0.63^{*}+\dagger$ & - & - & - & - \\
\hline 6. & Social Support & 18.51 & 3.32 & 0.71 & $0.28^{*}$ & $0.26^{*}$ & $0.15^{*}$ & $0.52^{*}+\dagger$ & $0.39^{*} \dagger$ & & - & - \\
\hline 7. & Advancement & 10.28 & 3.51 & 0.77 & $0.21^{*}$ & $0.24^{*}$ & $0.18^{*}$ & $0.42^{*} \dagger$ & $0.42^{*} \dagger$ & $0.23^{*}$ & - & - \\
\hline 8. & Job Insecurity & 8.28 & 3.03 & 0.89 & $0.05^{*}$ & $0.09^{*}$ & -0.03 & -0.03 & 0.03 & 0.01 & $-0.12^{*}$ & - \\
\hline 9. & Job Demands & 22.33 & 4.23 & 0.76 & 0.03 & $0.03^{*}$ & $0.20^{*}$ & $-0.06^{*}$ & $0.14^{*}$ & $-0.06^{*}$ & $-0.07^{*}$ & $0.03^{*}$ \\
\hline
\end{tabular}

${ }^{*} p<0.05$ - statistically significant; $\dagger r>0.30$ : practically significant (medium effect); $\ddagger r>0.50$ : practically significant (large effect); $S D$ standtard divaition 
TABLE 7

Results of the canonical analysis: Job demands, job resources, and employee engagement

\begin{tabular}{lcc}
\hline & \multicolumn{2}{c}{ First canonical variate } \\
\cline { 2 - 3 } & Correlation & Coefficient \\
\hline Employee Engagement Set & -0.85 & -0.22 \\
Vigour & -0.99 & -0.78 \\
Dedication & -0.64 & -1.26 \\
Absorption & 0.70 & - \\
Percent of Variance & 0.25 & - \\
Redundancy & & \\
& & \\
Job Demands/Resources Set & -0.75 & -0.21 \\
Organisational Support & -0.98 & -0.86 \\
Growth Opportunities & -0.45 & -0.13 \\
Social Support & -0.40 & 0.04 \\
Advancement & -0.13 & -0.11 \\
Job Insecurity & -0.08 & 0.04 \\
Job Demands & 0.12 & - \\
Percent of Variance & 0.32 & - \\
Redundancy & 0.61 & - \\
Canonical correlation &
\end{tabular}

\section{Multivariate statistics}

Canonical analysis was done between the three dimensions of employee engagement measured by the UWES and JD-RS. Table 7 shows the correlations between the variables and canonical variates, standardised canonical variate coefficients, and the within-set variance accounted for by the canonical variates (percent of variance), redundancies and canonical correlations.

The first canonical correlation is 0.61 (36.60\% overlapping variance). The other two canonical correlations are 0.26 and 0.12 . With all three canonical correlations included $F(18,10652.34)$ $=123.73, p<0,0001$. The second F-test $[F(10,7534)=31.25, p<$ $0.0001]$ and the third F-test $[F(4,3768)=13.36, p<0.0001]$ are also statistically significant. The three pairs of canonical variates, therefore, accounted for the significant relationships between the two sets of variables.
With a cut-off correlation of 0.30 , the variables in the employee engagement set that correlate with the first canonical variate are vigour (-0.85), dedication (-0.99) and absorption (-0.64). As far as job demands and resources are concerned it is organisational support $(-0.75)$, growth opportunities $(-0.98)$, social support $(-0.45)$ and advancement $(-0.40)$ that correlate with the first canonical variate. A series of multiple regression analyses were performed to determine the relationships between job demands, job resources, and employee engagement (see Table 8).

Table 8 shows that job demands and resources predict $36 \%$ of the variance in vigour $(F=229.50, p<0.01)$. The beta coefficients of four job resources, namely organisational support $(\beta=0.13$, $p<0.01)$, growth opportunities $(\beta=0.41, p<0.01)$, social support $(\beta=0.06, p<0.01)$, and job insecurity $(\beta=0.04, p<0.01)$ are statistically significant. Table 8 shows that job demands and resources predict $36 \%$ of the variance in dedication. The beta coefficients of three job resources, namely organisational support $(\beta=0.12, p<0.01)$, growth opportunities $(\beta=0.52, p$ $<0.01)$ and job insecurity $(\beta=0.08, p<0.01)$ are statistically significant, while the beta coefficient for job demands is also statistically significant $(\beta=-0.04, p<0.01)$. Table 8 also shows that job demands and resources predict $19 \%$ of the variance in absorption. The beta coefficients of three job resources, namely organisational support $(\beta=0.12, p<0.01)$, growth opportunities $(\beta=0.30, p<0.01)$ and job insecurity $(\beta=-0.04, p<0.01)$ are statistically significant. The beta coefficient of job demands is also statistically significant $(\beta=0.16, p<0.01)$. These results provide support for Hypothesis 6a.

Next, the interactions between job demands and job resources in terms of vigour, dedication and absorption were analysed. The predictor and moderator were entered into the regression equation first, followed by the interaction of the predictor and the moderator. The results of a series of hierarchical multiple regression analyses showed that the $R^{2}$ did not increase statistically significantly when the interaction terms between the predictor and moderator were entered into the regression

TABLE 8

Regression analyses of psychological conditions and antecedent factors as independent variables on employee engagement as dependent variable

\begin{tabular}{|c|c|c|c|c|c|c|c|c|c|}
\hline \multirow[t]{2}{*}{ Model } & & \multicolumn{2}{|c|}{ Unstandardised Coefficients } & \multirow{2}{*}{$\frac{\text { Standardised Coefficients }}{\text { Beta }}$} & \multirow[t]{2}{*}{$t$} & \multirow[t]{2}{*}{$p$} & \multirow[t]{2}{*}{$F$} & \multirow[t]{2}{*}{$R$} & \multirow[t]{2}{*}{$R^{2}$} \\
\hline & & B & $\overline{\mathrm{SE}}$ & & & & & & \\
\hline \multirow[t]{8}{*}{ Vigour } & & - & - & - & - & - & $229.50^{\star}$ & 0.60 & 0.36 \\
\hline & (Constant) & 6.13 & 0.72 & - & 8.54 & 0.00 & - & - & - \\
\hline & Organisational Support & 0.08 & 0.01 & 0.13 & 6.35 & $0.00^{*}$ & - & - & - \\
\hline & Growth Opportunities & 0.45 & 0.02 & 0.41 & 21.19 & $0.00^{*}$ & - & - & - \\
\hline & Social Support & 0.11 & 0.03 & 0.06 & 3.73 & $0.00^{*}$ & - & - & - \\
\hline & Advancement & -0.04 & 0.03 & -0.03 & -1.56 & 0.12 & - & - & - \\
\hline & Job Insecurity & 0.07 & 0.03 & 0.04 & 2.48 & $0.01^{*}$ & - & - & - \\
\hline & Job Demands & -0.03 & 0.02 & -0.02 & -1.52 & 0.13 & - & - & - \\
\hline \multirow[t]{8}{*}{ Dedication } & & & & & & & $347.57^{*}$ & 0.60 & 0.36 \\
\hline & (Constant) & 4.59 & 0.77 & - & 6.00 & 0.00 & & & \\
\hline & Organisational Support & 0.08 & 0.01 & 0.12 & 6.13 & $0.00^{*}$ & - & - & - \\
\hline & Growth Opportunities & 0.66 & 0.02 & 0.52 & 29.17 & $0.00^{*}$ & - & - & - \\
\hline & Social Support & -0.01 & 0.03 & -0.01 & -0.33 & 0.74 & - & - & - \\
\hline & Advancement & -0.04 & 0.03 & -0.02 & -1.44 & 0.15 & - & - & - \\
\hline & Job Insecurity & 0.18 & 0.03 & 0.08 & 6.10 & $0.00^{*}$ & - & - & - \\
\hline & Job Demands & -0.06 & 0.02 & -0.04 & -2.76 & $0.01^{*}$ & - & - & - \\
\hline \multirow[t]{8}{*}{ Absorption } & & & & & & & $144.78^{*}$ & 0.43 & 0.19 \\
\hline & (Constant) & 5.86 & 0.90 & - & 6.52 & 0.00 & - & - & - \\
\hline & Organisational Support & 0.09 & 0.02 & 0.12 & 5.73 & $0.00^{*}$ & - & - & - \\
\hline & Growth Opportunities & 0.40 & 0.03 & 0.30 & 14.86 & $0.00^{*}$ & - & - & - \\
\hline & Social Support & -0.04 & 0.04 & -0.02 & -1.19 & 0.23 & - & - & - \\
\hline & Advancement & 0.02 & 0.03 & 0.01 & 0.60 & 0.55 & - & - & - \\
\hline & Job Insecurity & -0.09 & 0.03 & -0.04 & -2.74 & $0.01^{*}$ & - & - & - \\
\hline & Job Demands & 0.27 & 0.03 & 0.16 & 10.79 & $0.00^{*}$ & - & - & - \\
\hline
\end{tabular}

${ }^{*} p<0.05-$ statistically significant 
analysis for vigour, dedication and absorption. Hypothesis $6 \mathrm{~b}$ is therefore rejected.

\section{DISCUSSION}

The objective of this study was to investigate the factors associated with employee engagement in South Africa from two models, namely the personal engagement model of Kahn (1990), and the work engagement model of Schaufeli and Bakker (2004). Regarding the personal engagement model of Kahn (1990), the results showed that psychological meaningfulness and psychological availability were positively associated with employee engagement. Psychological meaningfulness and psychological availability were positively associated with work role fit, co-worker and supervisor relations, facilitative norms and low self-consciousness. Psychological meaningfulness, which was the strongest predictor of employee engagement, mediated the relationship between work role fit and employee engagement. Regarding the work engagement model of Schaufeli and Bakker (2004), the results showed that job resources (including growth opportunities, organisational support, social support, and advancement) were positively associated with employee engagement (vigour, dedication, and absorption). Growth opportunities (such as learning opportunities, autonomy, and variety) had the strongest effect on employee engagement.

The results of this study support the findings of Shamir (1999) and May et al. (2004), namely that the psychological condition of meaningfulness is the strongest predictor of employee engagement, while work role fit is the strongest predictor of psychological meaningfulness. When employees see their roles as opportunities to express themselves they will experience a sense of meaning. Strümpfer (2003) also stressed the importance of work as a source of meaning in life. Furthermore, the results confirmed the importance of psychological availability as a predictor of employee engagement. Resources showed a positive association with psychological availability, but not with employee engagement, as was expected (see May et al., 2004).

As hypothesised, supervisor relations, co-worker relations, and co-worker norms were positively associated with employee engagement in this study. These findings confirm the findings of May et al. (2004). These three factors seem to have a direct effect on employee engagement. Regression analysis showed that when these three drivers of employee engagement were entered into a regression equation, only supervisor relations and co-worker norms were statistically significant. Rewarding interpersonal interaction with co-workers was however not statistically significantly related to psychological meaningfulness, which is contrary to the findings of Locke and Taylor (1990), Kahn (1990) and May et al. (2004). Supervisor relations and co-worker norms impacted on employee engagement, even when psychological safety was controlled for. Although these findings are in line with those of Kahn (1990), Edmondsen (2004) and May et al. (2004), it is evident that the effects of both supervisor relations and co-worker norms on employee engagement were small.

Only one of the above-mentioned three factors, namely supervisor relations, was related to psychological safety. However, statistically, psychological safety did not significantly predict employee engagement in this study. Therefore, psychological safety did not mediate the relationship between supervisor relations, co-worker relations and co-worker norms as expected. These results are contradictory to the findings of May et al. (2004), namely that psychological safety displayed a strong relation with employee engagement and partially mediated the effect of adherence to co-worker norms and employee engagement. This can be explained by the relatively poor reliability of the scale that was used to measure psychological safety. Psychological safety is regarded as an important construct, because it promotes positive emotions, enables individuals to find personal connection, and to both learn and unlearn new behaviours (Pratt \& Ashforth, 2003). Lower self-consciousness and supervisor relations were positively associated with psychological availability, but not with employee engagement.

Canonical analysis showed that employee engagement (i.e. vigour, dedication and absorption) was strongly related to four categories of job resources, namely, (1) growth opportunities (i.e. variety, learning opportunities and autonomy), (2) organisational support (i.e. the relationship with the manager, participation, communication, role clarity and information), (3) social support and (4) advancement. This result confirms the findings of previous studies (e.g. Hakanen et al., 2008; Rothmann \& Joubert, 2007; Rothmann \& Pieterse, 2007, Schaufeli \& Bakker, 2004). Regression analyses showed that $36 \%$ of the variance in vigour and dedication was explained by job resources, with growth opportunities and organisational support as the strongest predictors. As hypothesised by Schaufeli and Bakker (2004), job resources may play either an intrinsic motivational role by fostering the employee's growth, learning and development, or an extrinsic motivational role by being instrumental in achieving work goals.

Multiple regression analysis showed that absorption (which can be regarded as the cognitive component of employee engagement) is predicted by factors intrinsic to the job (such as variety, learning opportunities, and independence), factors extrinsic to the job (e.g. support from the organisation) and job demands. It seems that employees become more absorbed in their work when they have high demands, especially if growth opportunities and organisational support are also high. Job demands did not interact with job resources to effect employee engagement, which contradicts the results of some studies (see Bakker et al., 2008).

The finding that job resources impacted strongly on employee engagement provides support for the COR theory (Hobfoll, 1998). When organisations do not provide sufficient job resources (e.g. organisational support, growth opportunities, advancement opportunities and social support), the long-term consequences include withdrawal from work and reduced motivation and commitment (Hobfoll, 1998). Although work role fit was found to be a strong predictor of psychological meaningfulness, it will probably only be the case when employees are given the resources and opportunities to actually perform their work (Pratt \& Ashforth, 2003).

It is necessary to understand how engagement develops. This requires more than a list of potential antecedents of engagement; rather, the underlying mechanisms must be identified and explained (Meyer \& Gagné, 2008). No studies have been found where the mechanisms through which job demands and resources affect employee engagement in the model of Schaufeli et al. (2002) have been studied. One possibility is to use self-determination theory (Ryan \& Deci, 2002) to study such mechanisms. According to self-determination theory, the key to autonomous regulation is satisfaction of basic psychological needs for competence, autonomy and relatedness. The lack of satisfaction of these needs leads to poor performance and reduced physical and psychological well-being (Ryan \& Deci, 2000). Need satisfaction also mediates the relation between environmental influences (e.g. job demands and resources) and autonomous regulation of behaviour (Gagné \& Deci, 2005). The results of this study showed that growth opportunities in the job (i.e. variety of learning opportunities and autonomy) and organisational support are indeed strong predictors of employee engagement, possibly because these factors satisfy employees' needs for competence and autonomy. Support from supervisors (which is a sub-dimension of organisational support) and colleagues might affect engagement because 
these factors might satisfy employees' needs for relatedness. Self-determination theory might therefore be an important framework for understanding the underlying mechanisms in the development of employee engagement. Another possibility is to add psychological empowerment theory (Spreitzer, 1995) to the mechanisms through which job demands and resources affect employee engagement (see Stander \& Rothmann, in press).

The engagement model of Kahn (1990) conceptualises psychological conditions which mediate the effects of specific antecedents on employee engagement. The mediating effect of psychological meaningfulness has been shown in this study. However, more research is needed to develop a reliable and valid scale that could be used to study the relationship between psychological safety, antecedents thereof and employee engagement. Although this study showed that psychological availability predicts employee engagement, the relationship thereof to physical, emotional and cognitive resources should be clarified in future studies. It might also be possible to integrate the engagement models of Kahn (1990) and Schaufeli and Bakker (2004). The model of Kahn (1990) provides important insights regarding psychological conditions which mediate between work-related factors and employee engagement. The model of Schaufeli and Bakker (2004), on the other hand, might provide important insights regarding the relationships between job demands, job resources, psychological availability and employee engagement.

On conclusion of this study, the authors suggest that various aspects should be addressed to increase the engagement of employees. Firstly, interventions should be made to ensure the work role fit of employees, as well as variety, learning opportunities and autonomy in their jobs, which will contribute to experiences of psychological meaningfulness and engagement. Secondly, interventions should be implemented to ensure organisational support, including role clarity, good relationships with supervisors, communication, information and participation in decision-making. Thirdly, advancement opportunities (remuneration, promotion and training) should be addressed.

This study has several limitations. Firstly, a survey design was used, which makes it impossible to prove the causality of the obtained relationships. It is necessary to study the drivers of employee engagement in a longitudinal design. Secondly, the reliability of the WES (May et al., 2004) was less than optimal. More research is needed to develop a scale that is reliable, but also measures the physical, emotional and cognitive components of engagement. Thirdly, only three types of demands, namely pace and amount of work, quantitative load and emotional load were studied. Other demands, such as work-home interference and home-work interference were not studied, and should be included in future studies. Fourthly, the relationships between the intrinsic nature of a job, psychological conditions, and employee engagement were not considered in this study.

The following suggestions for future research regarding employee engagement can be made. Firstly, it is necessary to develop a scale with acceptable psychometric properties that can be used to measure the cognitive, emotional, and physical components of employee engagement. One solution is to use the UWES (Schaufeli et al., 2002), but the scale has to be adapted because at least one item of the UWES measures psychological meaningfulness rather than the emotional component of engagement. Secondly, research has to be conducted regarding the mechanisms through which job conditions affect employee engagement. Theories such as self-determination theory (Ryan \& Deci, 2002) and psychological empowerment theory (Spreitzer, 1995) can be considered in this regard. More research is also needed to develop the psychological safety scale (May et al., 2004). Thirdly, longitudinal research should be conducted to investigate the causal relationships between work-related factors, psychological conditions and employee engagement. Such studies could make use of ecological momentary assessment to investigate daily variations in employee engagement and its causes, specifically because it seems that there is substantial variation in daily experiences of these factors (Strydom \& Rothmann, in press). Lastly, continuous employee engagement may lead to stress and burnout. Therefore, research is needed on ways not only to promote employee engagement, but also on interventions that will be effective in preventing distress and burnout in engaged employees.

\section{REFERENCES}

Aiken, L.S., \& West, S.G. (1991). Multiple regression: Testing and interpreting interactions. Thousand Oaks: Sage.

Bakker, A.B., Demerouti, E., \& Schaufeli, W.B. (2003). Dual processes at work in a call centre: An application of the job demands-resources model. European Journal of Work and Organizational Psychology, 12, 393-417.

Bakker, A.B., Schaufeli, W.B., Leiter, M.P., \& Taris, T.W. (2008). Work engagement: An emerging concept in occupational health psychology. Work and Stress, 22, 187-200.

Barkhuizen, N., \& Rothmann, S. (2006). Work engagement of academic staff in South African higher education institutions. Management Dynamics, 15(1), 38-48.

Baron, R.M., \& Kenny, D.A. (1986). The moderator-mediator variable distinction in social psychological research: Conceptual, strategic, and statistical considerations. Journal of Personality and Social Psychology, 51, 1173-1182.

Cohen, J. (1988). Statistical power analysis for the behavioural sciences (rev. edn.). Orlando: Academic Press.

Demerouti, E., Bakker, A.B., Nachreiner, F., \& Schaufeli, W.B. (2001). The job demands-resources model of burnout. Journal of Applied Psychology, 86, 499-512.

Edmondson, A. (2004). Psychological safety and learning behaviour in work teams. Administrative Science Quarterly, 44, 350-383.

Feldman, D. (1984). The development and enforcement of group norms. Academy of Management Review, 9, 47-53.

Fourie, L., Rothmann, S., \& Van de Vijver, A.J.R. (2008). A model of work wellness for non-professional counsellors in South Africa. Stress and Health, 24, 35-47.

Gagné, M., \& Deci, E.L. (2005). Self-determination theory and work motivation. Journal of Organizational Behavior, 26, 331362.

Ganster, D.C., \& Schaubroeck, J. (1991). Work stress and employee health. Journal of Management, 17, 235-271.

Hackman, J.R., \& Oldham, G.R. (1980). Work redesign. Reading: Addison-Wesley.

Hakanen, J.J., Schaufeli, W.B., \& Ahola, K. (2008). The job demands-resources model: A three-year cross-lagged study of burnout, depression, commitment, and work engagement. Work and Stress, 22, 224-241.

Harter, J.K., Schmidt, F.L., \& Hayes, T.L. (2002). Business-unitlevel relationship between employee satisfaction, employee engagement and business outcomes: A meta-analysis. Journal of Applied Psychology, 87, 268-279.

Hobfoll, S.E. (1989). Conservation of resources: A new attempt at conceptualizing stress. American Psychologist, 44, 513-524.

Hobfoll, S.E. (1998). The psychology and philosophy of stress, culture, and community. New York: Plenum Books.

Hochschild, A. (1983). The managed heart. Berkeley: University of California Press.

Hollenbeck, J.R., Ilgen, D.R., \& Crampton, S.M. (1992). Lower back disability in occupational settings: A review of the literature from a human resource management view. Personnel Psychology, 45, 247-278.

Jackson, L.T.B., Rothmann, S., \& Van de Vijver, A.J.R. (2006). A model of work-related well-being for educators in South Africa. Stress and Health, 22, 263-274.

Kahn, W.A. (1990). Psychological conditions of personal engagement and disengagement at work. Academy of Management Journal, 33, 692-724. 
Locke, E.A., \& Taylor, M.S. (1990). Stress, coping and the meaning of work. In A. Brief \& W.R. Nord (Eds.), Meanings of occupational work (pp. 135-170). Lexington: Lexington Books.

Macey, W.H., \& Schneider, B. (2008). The meaning of employee engagement. Industrial and Organizational Psychology, 1, 3-30.

Maslach, C., \& Leiter, M.P. (1997). The truth about burnout: How organizations cause personal stress and what to do about it, San Francisco: Jossey-Bass.

Mauno, S., Kinnunen, U., \& Ruokolainen, M. (2007). Job demands and resources as antecedents of work engagement: A longitudinal study. Journal of Vocational Behavior, 70, 149-171.

May, D.R., Gilson, R.L., \& Harter, L.M. (2004). The psychological conditions of meaningfulness, safety and availability and the engagement of the human spirit at work. Journal of Occupational and Organizational Psychology, 77, 11-37.

McAllister, D.J. (1995). Affect- and cognition-based trust as foundations for interpersonal cooperation in organizations. Academy of Management Journal, 38, 24-59.

Meyer, J.P., \& Gagné, M. (2008). Employee engagement from a self-determination theory perspective. Industrial and Organizational Psychology, 1, 60-62.

Morris, J.A., \& Feldman, D.C. (1996). The dimensions, antecedents, and consequences of emotional labor. Academy of Management Review, 21, 986-1010.

Nunnally, J.C., \& Bernstein, I.H. (1994). Psychometric theory (3rd edn.). New York: McGraw-Hill.

Olivier, A.L., \& Rothmann, S. (2007). Antecedents of work engagement in a multinational oil company. South African Journal of Industrial Psychology, 33(3), 49-56.

Peterson, C., Nansook, P., \& Seligman, M.E.P. (2005). Orientations to happiness and life satisfaction: The full life versus the empty life. Journal of Happiness Studies, 6, 25-41.

Podsakoff, P.M., \& Organ, D.W. (1986). Self-reports in organizational research: Problems and prospects. Journal of Management, 12, 531-544.

Pratt, M.G., \& Ashforth, B.E. (2003). Fostering meaningfulness in work and working. In K.S. Cameron, J.E. Dutton \& R.E. Quinn (Eds.), Positive organizational scholarship: Foundations of a new discipline (pp. 309-327). San Francisco: BerrettKoehler Publishers.

Rothmann, S. (2003). Burnout and engagement: A South African perspective. South African Journal of Industrial Psychology, 29(4), 16-25.

Rothmann, S., \& Joubert, J.H.M. (2007). Job demands, job resources, burnout and work engagement of management staff at a platinum mine in the North West Province. South African Journal of Business Management, 38(3), 49-61.

Rothmann, S., \& Pieterse, A.J.H. (2007). Predictors of workrelated well-being in Sector Education and Training Authorities. South African Journal of Economic and Management Sciences, 10, 298-312.

Rothmann, S., Strydom, M., \& Mostert, K. (2006). A psychometric evaluation of the Job Demands-Resources Scale in South Africa. South African Journal of Industrial Psychology, 32(4), 76-86.

Ryan, R.M., \& Deci, E.L. (2000). Self-determination theory and the facilitation of intrinsic motivation, social development, and well-being. American Psychologist, 55, 68-78.
Ryan, R.M., \& Deci, E. L. (2001). On happiness and human potentials: A review of research on hedonic and eudaimonic well-being. Annual Review of Psychology, 52, 141-166.

Ryan, R.M., \& Deci, E.L. (2002). Overview of self-determination theory: An organismic-dialectical perspective. In E.L. Deci \& R.M. Ryan (Eds.), Handbook of self-determination research (pp. 3-33). Rochester: The University of Rochester Press.

Saks, A.M. (2006). Antecedents and consequences of employee engagement. Journal of Managerial Psychology, 21, 600-619.

Salanova, M., Llorens, S., Cifre, E., Martinez, I., \& Schaufeli, W.B. (2003). Perceived collective efficacy, subjective wellbeing and task performance among electronic work groups: An experimental study. Small Group Research, 34, 43-73.

Schaufeli, W.B., \& Bakker, A.B. (2004). Job demands, job resources and their relationship with burnout and engagement: A multi-sample study. Journal of Organizational Behavior, 25, 293-315.

Schaufeli, W.B., Salanova, M., González-Romá, V., \& Bakker, A.B. (2002). The measurement of engagement and burnout: A two sample confirmatory factor analytic approach. Journal of Happiness Studies, 3, 71-92.

Seeman, M. (1972). Alienation and engagement. In A. Campbell \& P.E. Converce (Eds.), The human meaning of social change (pp. 467-527). New York: Russell Sage Foundation.

Seligman, M.E.P., \& Csikszentmihalyi, M. (2000). Positive psychology: An introduction. American Psychologist, 55, 5-14.

Shamir, B. (1991). Meaning, self and motivation in organizations. Organization Studies, 12, 405-424.

Sonnentag, S. (2003). Recovery, work engagement, and proactive behavior: A new look at the interface between non-work and work. Journal of Applied Psychology, 88, 518-528.

Spreitzer, G.M. (1995). Psychological empowerment in the workplace: Dimensions, measurement and validation. Academy of Management Journal, 38, 1442-1465.

SPSS Inc. (2008). SPSS 16.0 for Windows. Chicago: SPSS Inc.

Stander, M.W., \& Rothmann, S. (2010). Psychological empowerment, job insecurity, and employee engagement. SA Journal of Industrial Psychology, 36(1), 1-8. DOI:10.4102/ sajip.v36i1.849.

Steyn, H.S. (1999). Praktiese betekenisvolheid: Die gebruik van effekgroottes [Practical significance: The use of effect sizes]. Wetenskaplike bydraes - Reeks B: Natuurwetenskappe Nr. 117. Potchefstroom: Potchefstroomse Universiteit vir Christelike Hoër Onderwys (nou Noordwes Universiteit).

Storm, K., \& Rothmann, S. (2003). The validation of the Utrecht Work Engagement Scale in the South African Police Services. South African Journal of Industrial Psychology, 29(4), 62-70.

Strümpfer, D.J.W. (2003). Resilience and burnout: A stitch that could save nine. South African Journal of Psychology, 33, 69-79.

Strydom, M., \& Rothmann, S. (in press). Work engagement and psychological conditions: Exploring daily variations.

Sutton, R.I. (1991). Maintaining norms about expressed emotions: The case of the bill collectors. Administrative Science Quarterly, 36, 245-268.

Tabachnick, B.G., \& Fidell, L.S. (2001). Using multivariate statistics. (4th edn.). Boston: Allyn \& Bacon.

Thomas, K.W., \& Velthouse, B.A. (1990). Cognitive elements of empowerment: An 'interpretive' model of intrinsic task motivation. Academy of Management Review, 15, 666-681. 